\section{Pacific Northwest}

National Laboratory

Operated by Battelle for the

U.5. Department of Energy

\title{
Independent Evaluation of The Lepestok Filtering Facepiece Respirator
}

\author{
M. D. Hoover J. R. Lackey \\ Lovelace Respiratory Research Institute \\ G.J. Vargo \\ Pacific Northwest National Laboratory
}

July 2001

Prepared for the U.S. D epartment of Energy under Contract DE-AC06-76RL01830 


\section{Disclaimer}

This report was prepared as an account of work sponsored by the United States Government. Neither the United States Government nor the United States Department of Energy, nor any of its employees, nor any of their contractors, subcontractors, or their employees, makes any warranty, expressed or implied, or assumes any legal liability or responsibility for the accuracy, completeness, or usefulness of any information, apparatus, product or process disclosed, or represents that its use would not infringe on privately owned rights. 


\title{
Independent Evaluation of The Lepestok Filtering Facepiece Respirator
}

July, 2001

\author{
Mark D. Hoover, PhD, CHP, CIH \\ and Jack R. Lackey \\ Lovelace Respiratory Research Institute \\ P.O. Box 5890 \\ Albuquerque, NM 87185-5890 \\ Phone: 505-845-1040; Fax: 505-845-1180 \\ mhoover@LRRI.org \\ and \\ George J. Vargo, PhD., CHP \\ International Nuclear Safety Program \\ Pacific Northwest National Laboratory \\ Phone: 509-375-6836; Fax: 509-375-2019 (fax) \\ vargo@pnl.gov

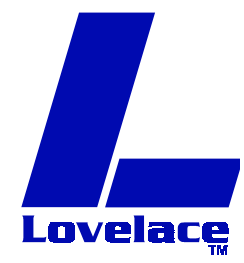

\section{LOVELACE RESPIRATORY RESEARCH INSTITUTE}

P.O. Box 5890

Albuquerque, NM 87185-5890

Research performed for the U.S. Department of Energy under Pacific Northwest National Laboratory Contract

No. 298148-A-N Media 


\section{Contents}

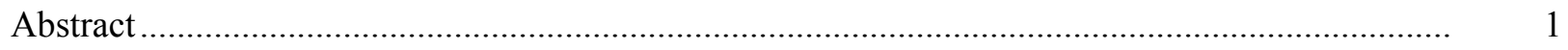

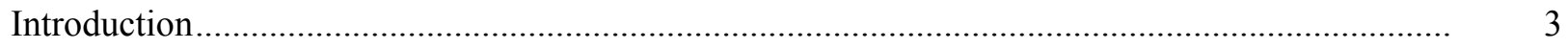

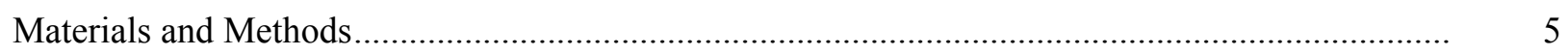

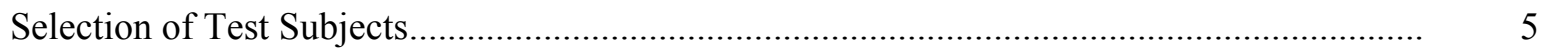

Definition of the Fit Factor ..............................................................................................

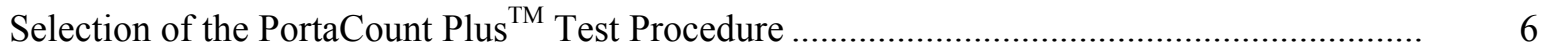

Separating the Roles of Filter Efficiency and Inleakage around the Facepiece ...................... 6

Description of the Test Procedure .................................................................................



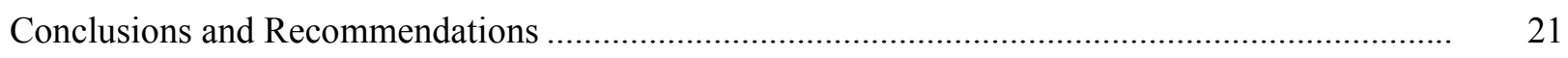

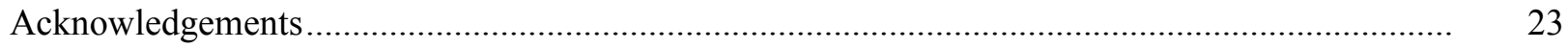

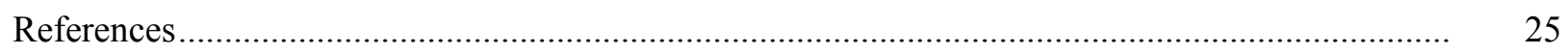




\section{Figures}

1 Side View of the Lepestok Filtering Facepiece Respirator

Being Worn in a Proper Manner by an Adult Male

2 Front View of Lepestok Filtering Facepiece Respirator

with an Aerosol Sampling Port Installed at the Center of the Mask

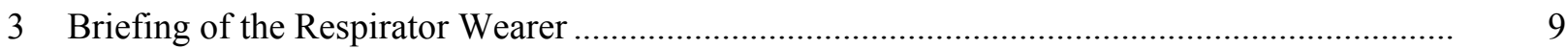

4 View of the Respirator and Aerosol Sampling Lines Ready for Testing ................................ 9

5 View of the Stationary Position of the Respirator Wearer During the Quantitative Fit Test...... 11

6 View of a Subject During Reading Out Loud of a Printed Passage ....................................... 11

7 Summary of the Pass-Fail Rates for Each of the Exercises and the Overall Test Pass Status .... 16

8 Rank Order of the Overall Fit Factors for All Fit Tests from Lowest Value of Highest Value .. 17

9 Rank Order of the Overall Fit Factors for Fit Tests 2 through 4

from Lowest Value to Highest Value.

\section{Tables}

1 Numerical Values of the Fit Factors for Each of the Six Exercises and the Overall Fit Factor for all 100 of the Tests Conducted in This Study.

2 Percentage of All Test Exceeding a Given Overall Fit Factor

3 Summary of the Overall Pass-Fail Rates for all 25 Subjects in Each of the Four Tests.

4 Percentage of Tests 2 through 4 Exceeding a Given Overall Fit Factor

5 Performance of the Lepestok-200 Filtering Facepiece Respirator Compared to the Performance of 21 Other Models of N95 Respirators That were Tested by NIOSH ............ 


\begin{abstract}
The purpose of this study was to determine the protection factor of the Lepestok-200 filtering facepiece respirator by conducting a standard quantitative fit test on a panel of 25 representative adults (14 males and 11 females) using the TSI Incorporated PortaCount Plus ${ }^{\mathrm{TM}}$ quantitative fit-testing system. Each subject was tested four times. In the total of 100 tests, $95 \%$ of the overall fit factors were greater than 3 , more than $80 \%$ of the overall fit factors were greater than 14 , approximately $50 \%$ were greater than 86 , and $20 \%$ were greater than 200 . The pass-fail performance of the respirator was similar for each of the six exercises in the test series: (1) normal breathing, (2) deep breathing, (3) moving the head side to side, (4) moving the head up and down, (5) reading a passage of text out loud, and (6) normal breathing, indicating that the respirator performs equally well for each type of exercise. A significant and sustained improvement in fit factor was observed after the initial test, indicating that the subjects benefited from the knowledge gained in the first of the four quantitative fit tests. In the 75 tests conducted after the initial test for each individual, $95 \%$ of the overall fit factors were greater than 6 , more than $80 \%$ of the overall fit factors were greater than 23 , and $50 \%$ were greater than 116 , and $20 \%$ were greater than 200 . Thus, the initial learning experienced doubled the fit factor for subsequent tests. In addition, there is an indication that the Lepestok-200 may perform better on wearers with wider faces than on individuals with narrower faces. The results of this study demonstrate the effectiveness of the Lepestok-200 respirator and reinforce the general conclusion that quantitative fit-testing can make an important contribution to ensuring that proper protection factors are achieved for workers.
\end{abstract}




\section{Introduction}

The Lepestok-200 is a filtering respirator that is intended for the personal protection of the organs of respiration against harmful aerosols within rooms, underground excavations, and the open air (GOST 1976). The Lepestok-200 respirator was selected for evaluation because it is a popular, lightweight respirator that is currently being used at locations such as the Shelter Facility at Chornobyl. A recent independent evaluation has confirmed that the basic aerosol collection efficiency of the filter medium used in the Lepestok-200 is quite high ( $>\sim 95 \%$ at a linear air throughput velocity of $34 \mathrm{~cm} / \mathrm{s}$ ) (Hoover et al. 1999) and it has been noted (Suhoruchkin 2000) that the particle collection efficiency of the filter medium is designed to be even more efficient ( $>99.5 \%)$ under the typical air velocity conditions of 1 $\mathrm{cm} / \mathrm{s}$ that are expected in a filtering facepiece respirator. The purpose of the present study is to evaluate the protection factor of the Lepestok-200 filtering respirator in a quantitative fit test involving a standard panel of 25 adults. The results of such tests can provide information about how the respirator might function in the workplace, and about whether routine quantitative fit-testing might help match a given worker to a certain type of respirator. 


\section{Materials and Methods}

This study began by determining an appropriate classification for the Lepestok-200 respirator. The Lepestok-200 is considered to be similar in construction and efficiency to the class of particulate airpurifying respirators known in the United States as N95 half-face filtering facepiece respirators. The classification scheme for this type of respirator has been developed and described by the National Institute for Occupational Safety and Health (NIOSH 1996). There are three levels of filter efficiency (95\%, 99\%, and 99.97\%), each with three categories of resistance to filter degradation ( $\mathrm{N}, \mathrm{R}$, and $\mathrm{P}$ ), making nine classes of efficiency. An N95 filter is an N-category filter that is at least $95 \%$ efficient. These classifications are in addition to the traditional half-face, full-face, and other respirators that are designed to protect the wearer from the inhalation of hazardous atmospheres (ANSI 1992). N-category filters are the least resistant to degradation by oil aerosols.

The benefits of quantitative fit-testing for half-face filtering facepiece respirators have been described in a number of recent publications (NIOSH 1998, Coffey et al. 1998a, 1998b, 1999a, 1999b, and 2000, and Zhuang et al. 2000). It has been shown that quantitative fit-testing of N95 respirator models is needed to ensure that at least the expected level of protection is provided (i.e., that the concentration of airborne contaminants inside the respirator will be less than or equal to $10 \%$ of the levels outside the respirator). Quantitative fit-testing can identify individuals with facial features that are not suited to a particular type of respirator, and fit-testing can also provide a learning experience for respirator wearers regarding the need for proper donning and wearing of the respirator. In most cases, it has been shown that no single design and size of respirator is appropriate for all people. In many cases, several types of respirators must be evaluated to identify a respirator that meets the needs of a specific person.

\section{Selection of Test Subjects}

A panel of 25 subjects consisting of 14 males and 11 females was used to measure the performance of the Lepestok-200 respirator. Each subject was either familiar with or received an orientation on the proper donning and wearing of respirators. The subjects had facial sizes in accordance with the Los Alamos National Laboratory 25-member respirator panel for testing half-mask respirators (Hack et al. 1974). The protocol for using human subjects in this study was reviewed and approved by the Lovelace Respiratory Research Institute institutional review board. Each subject reviewed and signed a consent form before testing.

\section{Definition of the Fit Factor}

The respirator fit factor is a quantitative measure of the fit of a particular respirator to a particular individual. The fit factor can be determined quantitatively by using an instrument to measure the concentration of a challenge aerosol outside the respirator $\left(C_{\text {out }}\right)$ and dividing that number by the measured concentration inside the respirator $\left(C_{\text {in }}\right)$ (AIHA 1985). Thus, the fit factor is defined as the ratio $C_{\text {out }} / C_{\text {in }}$. As a point of reference, the American National Standard for Respiratory Protection (ANSI 1992) designates a minimum fit factor of 100 as the pass/fail criterion to determine if a half-mask respirator 
provides an adequate fit for use in the workplace. This provides some assurance that the actual fit factor in the workplace will be greater than or equal to 10 .

\section{Selection of the PortaCount Plus ${ }^{\mathrm{TM}}$ Test Procedure}

The TSI Incorporated PortaCount Plus ${ }^{\mathrm{TM}}$ quantitative fit-testing system with the N95 Companion ${ }^{\mathrm{TM}}$ attachment (TSI 1991, 1998a, and 1998b) was chosen for this study because it has been widely used in similar test programs, and the fit factors obtained from this instrument have been shown in a simulated health-care workplace to have a high correlation with a wearer's actual exposure (Coffey et al. 1999a, $1999 b$, and 2000). The PortaCount Plus ${ }^{\mathrm{TM}}$ system includes an ultrasonic aerosol generator that creates a salt aerosol of small particle size (about 0.025 to $0.055 \mu \mathrm{m}$ diameter particles) for detection by a miniature condensation nuclei counter.

The N95-Companion ${ }^{\mathrm{TM}}$ removes the aerosol particle size that makes the most penetration of the respirator filter (TSI 1998b and Coffey et al. 1999a) and bases the fit factor calculation on detection of particles for which there is no significant penetration of the small salt particles directly through the filter media. This assumption is valid for all particle sizes when a high efficiency particulate air (HEPA) filter medium is used. (By definition, a HEPA filter has a collection efficiency of greater than $99.97 \%$, and less than $0.03 \%$ of the most penetrating particle size of $0.3-\mu \mathrm{m}$ diameter will penetrate through a HEPA filter.) In such cases, any penetration of particles into the respirator is due entirely to leakage around the face. For lower efficiency filter media, which allow some penetration of particles through the filter medium, the PortaCount ${ }^{\mathrm{TM}}$ "fit factor" is actually a "protection factor" that takes all mechanisms of inleakage into account.

\section{Separating the Roles of Filter Efficiency and Inleakage around the Facepiece}

The effectiveness of a respirator depends on both the intrinsic efficiency of the filter medium and the physical fit of the respirator. An inefficient filter with a perfect fit can provide the same protection as an efficient filter with a poor fit. The intrinsic efficiency of the filter medium determines the upper limit for the overall performance of the respirator. For example, if the intrinsic collection efficiency of the filter medium is $99.5 \%$ then the penetration is $0.5 \%$ and the protection factor for a "perfectly fitting" respirator is:

$$
P F=\frac{C_{\text {out }}}{C_{\text {in }}}=\frac{1}{0.005}=200
$$

Thus, a value of 200 is the highest fit factor that can be achieved by a filter medium with an intrinsic efficiency of $99.5 \%$. Any leakage around the face piece will result in a lower value for the protection factor. 
Note that it is possible to separate the contributions of fit and filter penetration. Because filter penetration through an N95 respirator may be as great as 5\% by definition, Zhuang et al. (2000) have proposed a means of correcting or adjusting the PortaCount ${ }^{\mathrm{TM}}$ fit factor to account for filter penetration:

$$
A F F=\frac{M F F \bullet F F F}{(F F F-M F F)}
$$

where

$A F F$ is the adjusted fit factor (for leakage around the facepiece only),

$M F F$ is the measured "fit factor" for penetration of particles through a sample of the filter medium that has been well sealed in a test system, and

FFF is the fit factor measured by the standard PortaCount Plus ${ }^{\mathrm{TM}}$.

This approach can be used to separate the role of filter media collection efficiency from issues related to the design and implementation of the face seal for the respirator. For example, if the intrinsic efficiency of the Lepestok-200 filter medium is greater than $99.5 \%$, then any fit factor less than 200 is the result of leakage around the facepiece.

\section{Description of the Test Procedure}

Each subject was instructed on the proper procedure for donning and wearing the Lepestok-200 respirator. After instruction, the subject donned the mask without assistance. As shown in Figure 1, the subjects were advised that the retaining strap must be positioned above the ears, at or near the crown of the head, with sufficient tension to hold the mask to the face, but with sufficient looseness to prevent the mask from being distorted in the region of the face seal. The subjects were instructed in how to use the elastic cord in the edge of the respirator to adjust the shape of the mask on the face.

A special aerosol sampling port (Figure 2) was installed on each mask to provide a means of bringing aerosol from the inside of the mask to the PortaCount Plus ${ }^{\mathrm{TM}}$ sampling system. Installation of the port involves use of a special crimping tool to provide a leak-tight seal around the port. Each port was visually inspected to ensure proper installation. A certified test operator provided the instructions and supervised the tests (Figure 3). The aerosol sampling lines were attached both outside and inside the respirator and held in proper position by a neck strap unit (Figure 4). The subjects breathed normally through the system for several minutes to fully humidify the mask and the tubing. 




Figure 1. Side View of the Lepestok Filtering Facepiece Respirator Being Worn in a Proper Manner by an Adult Male. The retaining strap is positioned above the ears, at or near the crown of the head, with sufficient tension to hold the mask to the face, but with sufficient looseness to prevent the mask from being distorted in the region of the face seal. The elastic cord for adjusting the shape of the mask on the face can be seen protruding from the lower edge of the mask.

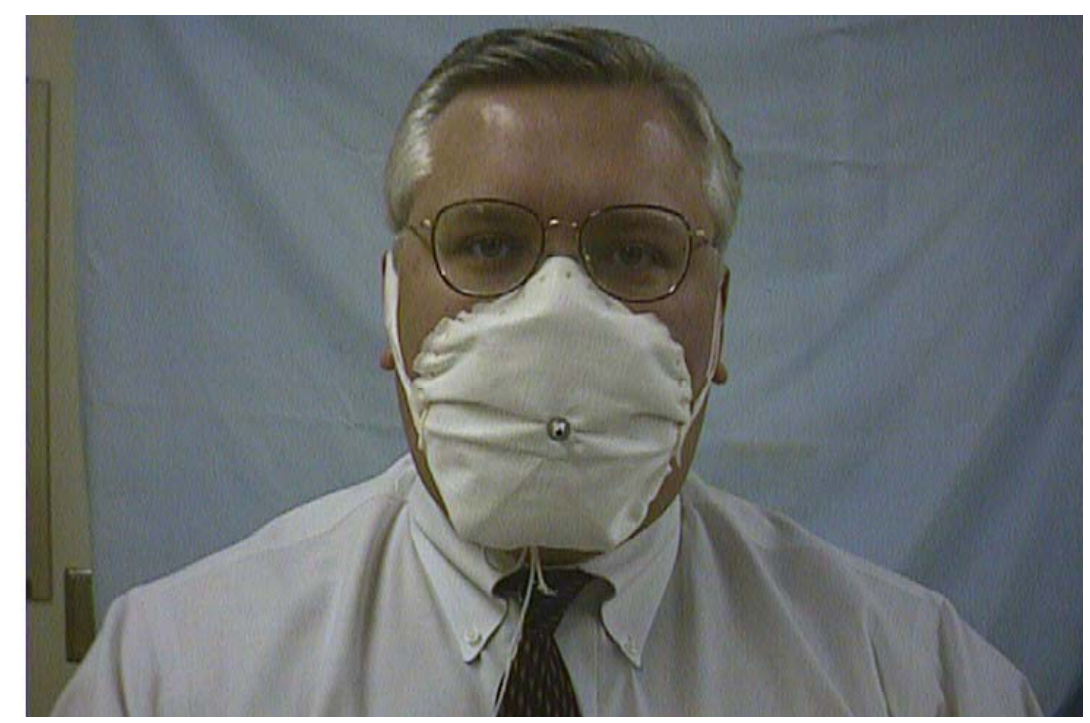

Figure 2. Front View of Lepestok Filtering Facepiece Respirator with an Aerosol Sampling Port Installed at the Center of the Mask. This configuration permits measurement of the aerosol concentration inside the mask during the quantitative fit-testing procedure. 




Figure 3. Briefing of the Respirator Wearer. The wearer is briefed by the certified quantitative fit test operator prior to quantitative fit-testing with the TSI PortaCount Plus ${ }^{\mathrm{TM}}$ system.

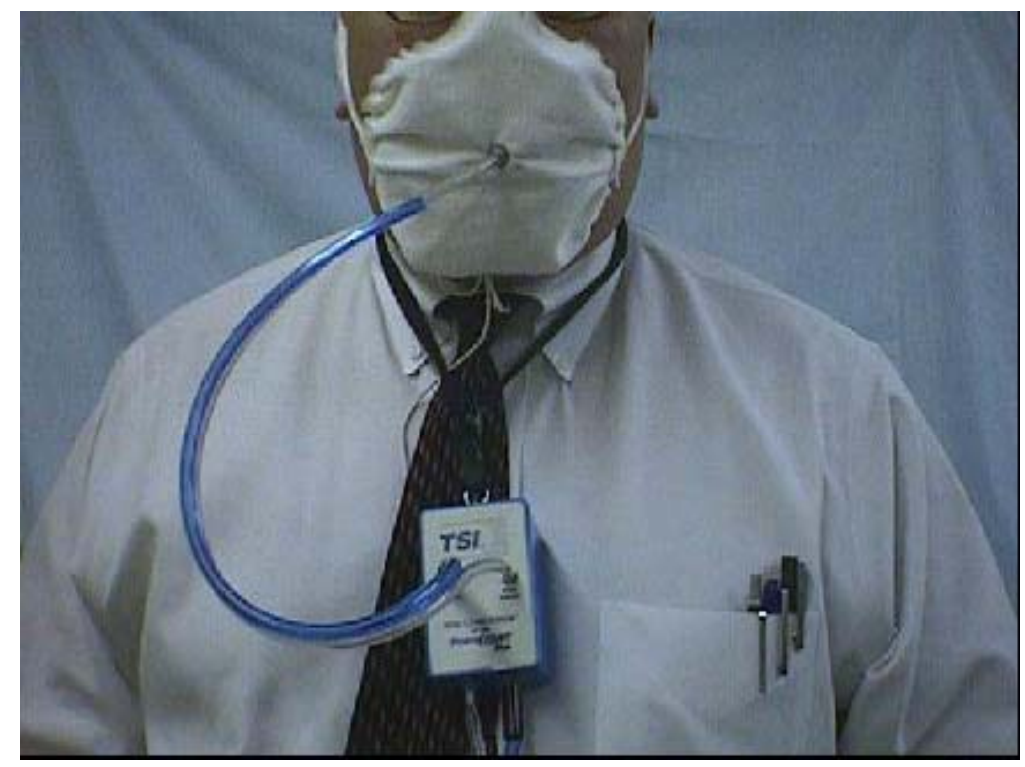

Figure 4. View of the Respirator and Aerosol Sampling Lines Ready for Testing. A neck strap unit is used to hold the aerosol sampling lines in the proper position. The sampling line for inside the mask is clear tubing and the sampling line for outside the mask is blue tubing. 
The standard respirator fit test (OSHA 1998) involved six test exercises that were performed sequentially for approximately 80 seconds each: (1) normal breathing, (2) deep breathing, (3) moving the head side to side, (4) moving the head up and down, (5) reading a passage of text out loud, and (6) normal breathing. The concentrations of particles inside and outside of the respirator were sequentially measured during each exercise. Fit factors were obtained for each individual exercise, and an overall fit factor was obtained for the entire exercise series. Because fit factor is the inverse of penetration, the overall fit factor is calculated as follows:

$$
F F=\frac{6}{\frac{1}{F F_{1}}+\frac{1}{F F_{2}}+\frac{1}{F F_{3}}+\frac{1}{F F_{4}}+\frac{1}{F F_{5}}+\frac{1}{F F_{6}}}
$$

Once an exercise series had begun, the subjects were not allowed to alter the position of the respirator because any such adjustment could cause inconsistent results from exercise to exercise. In addition, the subjects were required to remain in the same position relative to the PortaCount Plus ${ }^{\mathrm{TM}}$ system during the entire exercise series (Figure 5), including during reading out loud of the printed text (Figure 6).

Each subject was tested a total of four times. Two tests were performed in an initial session, and two tests were performed on a different day in a second session. The test schedule was arranged so that each subject would have one morning test session and one afternoon test session. The subjects were advised of the results of the tests as they were completed. This permitted some "learning" about how to adjust the respirator to achieve a good fit factor. After each test session, the Lepestok respirator being worn by a subject was allowed to dry in the open air and then was stored in a labeled and sealed plastic bag. Test subject numbers (rather than names) were used for labeling so that the confidentiality of the subjects would be maintained. If possible, the same respirator was used for up to four tests with an individual subject. This was done to provide data on the variation in the fit factor for an individual mask on same subject. This approach was also necessary because of the limited number of respirators that were available for use in the study. 


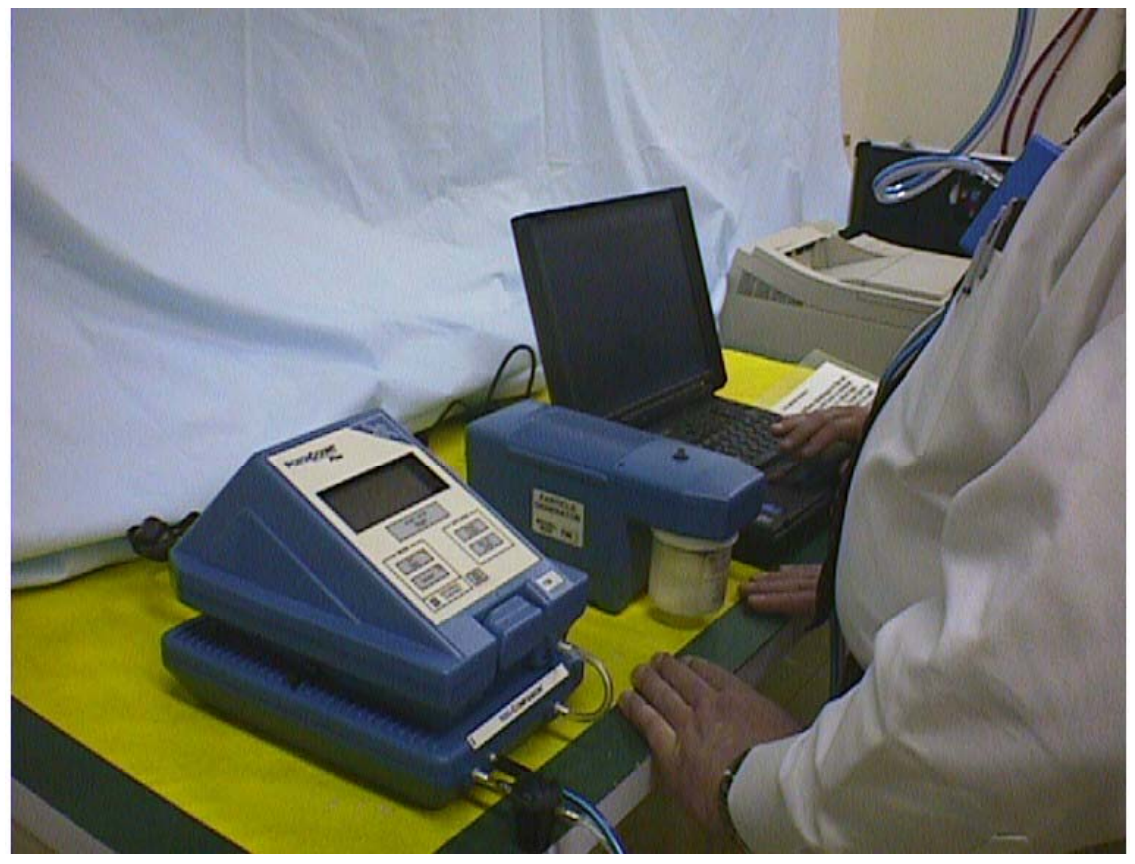

Figure 5. View of the Stationary Position of the Respirator Wearer During the Quantitative Fit Test. The ultrasonic salt aerosol generator module is on the right and the aerosol detection and data readout module is on the left. The connections for the aerosol sampling lines that collect aerosol from inside the mask and outside of the mask are located at the bottom left corner of the detection and readout module. The laptop computer for controlling the test and storing the data is on the far left.

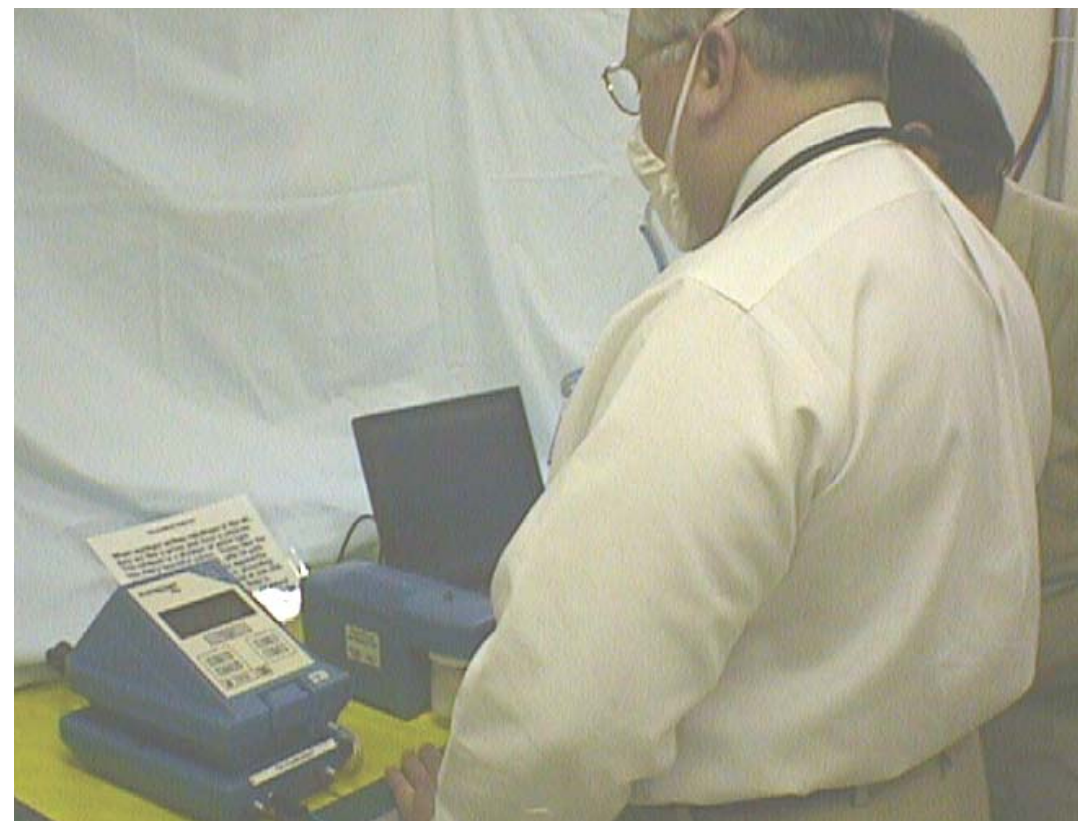

Figure 6. View of a Subject During Reading Out Loud of a Printed Passage. This view also shows the relative positions of the tubes for sampling inside and outside the respirator. 


\section{Results and Discussion}

Table 1 provides the numerical values of the fit factors for each of the six exercises and the overall fit factor for all 100 of the tests conducted in this study. The pass criterion was a fit factor greater than 100. As shown in Figure 7, the pass-fail performance of the respirator was similar for each of the six exercises in the test series (normal breathing, deep breathing, moving the head side to side, moving the head up and down, reading a passage of text out loud, and normal breathing, indicating that the respirator performs equally well for each type of exercise). The distribution of failure rates shown in Figure 7 also indicates that subjects cannot simply be divided in two groups based on "always passes" and "always fails." There are a number of subjects for whom the respirator sometimes passes and sometimes does not pass. The variability of fit factors is believed to result from the challenge of consistently providing a uniform seal between the folded edge of the respirator and the face of the wearer. There is also an indication that the Lepestok-200 may perform better on wearers with wider faces than on individuals with narrower faces. If a more detailed field study were done with an actual worker population, it may be possible to identify those individuals who would get better protection from a respirator with a different design.

Table 1. Numerical Values of the Fit Factors for Each of the Six Exercises and the Overall Fit Factor for all 100 of the Tests Conducted in This Study

\begin{tabular}{|c|c|c|c|c|c|c|c|c|}
\hline $\begin{array}{l}\text { Subject } \\
\text { Number }\end{array}$ & $\begin{array}{c}\text { Test } \\
\text { Number }\end{array}$ & $\begin{array}{c}\text { Normal } \\
\text { Breathing } \\
\text { Fit Factor }\end{array}$ & $\begin{array}{c}\text { Deep } \\
\text { Breathing } \\
\text { Fit Factor }\end{array}$ & \begin{tabular}{|c|} 
Head Side- \\
to-Side Fit \\
Factor
\end{tabular} & $\begin{array}{l}\text { Iead Up and } \\
\text { Down Fit } \\
\text { Factor } \\
\end{array}$ & $\begin{array}{c}\text { Talking } \\
\text { Fit } \\
\text { Factor }\end{array}$ & \begin{tabular}{|c|} 
Normal \\
Breathing \\
Fit Factor \\
\end{tabular} & $\begin{array}{c}\text { Overall } \\
\text { Fit Factor }\end{array}$ \\
\hline PNNLS-01 & $\begin{array}{l}\text { TEST } 1 \\
\end{array}$ & $\overline{c 58}$ & 35 & 44 & 40 & 84 & 27 & 42 \\
\hline PNNLS-01 & TEST 2 & $200+$ & $200+$ & 97 & 132 & 125 & 151 & 141 \\
\hline PNNLS-01 & TEST 3 & 27 & 101 & 120 & 133 & 13 & 35 & 35 \\
\hline PNNLS-01 & TEST 4 & 85 & 59 & 86 & 143 & 70 & 142 & 87 \\
\hline PNNLS-02 & TEST 1 & 49 & 76 & 66 & 53 & 37 & 55 & 53 \\
\hline PNNLS-02 & TEST 2 & 98 & 93 & 127 & 155 & $200+$ & 115 & 122 \\
\hline PNNLS-02 & TEST 3 & 61 & 61 & $200+$ & 99 & 137 & 68 & 86 \\
\hline PNNLS-02 & TEST 4 & 47 & 76 & 98 & 65 & 117 & 79 & 74 \\
\hline PNNLS-03 & TEST 1 & 2.2 & 5.8 & 0.9 & 1.4 & 2.6 & 0.8 & 1.5 \\
\hline PNNLS-03 & TEST 2 & 12 & 8.6 & 2.1 & 2.4 & 4.8 & 2.6 & 3.6 \\
\hline PNNLS-03 & TEST 3 & 127 & 82 & 105 & 97 & $200+$ & 84 & 106 \\
\hline PNNLS-03 & TEST 4 & 65 & 86 & 92 & 103 & 116 & 110 & 92 \\
\hline PNNLS-04 & TEST 1 & 6.9 & 5.8 & 2.6 & 6.1 & 2.0 & 1.7 & 3.1 \\
\hline PNNLS-04 & TEST 2 & 6.4 & 13 & 2.3 & 4.0 & 1.7 & 1.4 & 2.7 \\
\hline PNNLS-04 & TEST 3 & 23 & 28 & 62 & 18 & 6.0 & 5.3 & 12 \\
\hline PNNLS-04 & TEST 4 & 88 & 174 & 4.8 & 25 & 21 & 9.0 & 14 \\
\hline PNNLS-05 & TEST 1 & 10.0 & 8.7 & 9.9 & 1.9 & 7.7 & 4.7 & 5.1 \\
\hline PNNLS-05 & TEST 2 & 9.5 & 21 & 58 & 25 & 9.9 & 8.1 & 14 \\
\hline PNNLS-05 & TEST 3 & 14 & 50 & 22 & 43 & 111 & 21 & 28 \\
\hline PNNLS-05 & TEST 4 & 103 & 73 & 61 & 87 & 11 & 35 & 35 \\
\hline
\end{tabular}




\begin{tabular}{|c|c|c|c|c|c|c|c|c|}
\hline $\begin{array}{l}\text { Subject } \\
\text { Number }\end{array}$ & $\begin{array}{c}\text { Test } \\
\text { Number }\end{array}$ & $\begin{array}{c}\text { Normal } \\
\text { Breathing } \\
\text { Fit Factor }\end{array}$ & $\begin{array}{c}\text { Deep } \\
\text { Breathing } \\
\text { Fit Factor }\end{array}$ & $\begin{array}{l}\text { Head Side- } \\
\text { to-Side Fit } \\
\text { Factor } \\
\end{array}$ & $\begin{array}{l}\text { Jead Up and } \\
\text { Down Fit } \\
\text { Factor }\end{array}$ & $\begin{array}{c}\text { Talking } \\
\text { Fit } \\
\text { Factor }\end{array}$ & \begin{tabular}{|c|} 
Normal \\
Breathing \\
Fit Factor \\
\end{tabular} & $\begin{array}{c}\text { Overall } \\
\text { Fit Factor }\end{array}$ \\
\hline PNNLS-06 & TEST 1 & 59 & 61 & 33 & 27 & 24 & 7.2 & 21 \\
\hline PNNLS-06 & TEST 2 & $200+$ & $200+$ & $200+$ & $200+$ & $200+$ & $200+$ & 200 \\
\hline PNNLS-06 & TEST 3 & 78 & 127 & $200+$ & 132 & $200+$ & 72 & 115 \\
\hline PNNLS-06 & TEST 4 & 84 & $200+$ & 84 & $200+$ & $200+$ & 82 & 118 \\
\hline PNNLS-07 & TEST 1 & 4.6 & 7.3 & 22 & 121 & 21 & 17 & 12 \\
\hline PNNLS-07 & TEST 2 & 7.6 & 11 & 16 & 21 & 16 & 32 & 14 \\
\hline PNNLS-07 & TEST 3 & $200+$ & $200+$ & $200+$ & $200+$ & $200+$ & $200+$ & 200 \\
\hline PNNLS-07 & TEST 4 & 58 & 110 & 56 & 33 & $200+$ & 167 & 70 \\
\hline PNNLS-08 & TEST 1 & 16 & 8.0 & 12 & 15 & 5.5 & 4.1 & 7.8 \\
\hline PNNLS-08 & TEST 2 & 57 & 27 & 51 & 28 & 40 & 79 & 40 \\
\hline PNNLS-08 & TEST 3 & 113 & 38 & 38 & 51 & 87 & 34 & 49 \\
\hline PNNLS-08 & TEST 4 & 45 & 185 & $200+$ & 121 & 77 & 45 & 79 \\
\hline PNNLS-09 & TEST 1 & $200+$ & $200+$ & $200+$ & $200+$ & $200+$ & 157 & 191 \\
\hline PNNLS-09 & TEST 2 & 15 & 15 & 17 & 12 & 20 & 5.8 & 12 \\
\hline PNNLS-09 & TEST 3 & $200+$ & $200+$ & $200+$ & 148 & $200+$ & $200+$ & 189 \\
\hline PNNLS-09 & TEST 4 & 74 & 73 & $200+$ & $200+$ & 136 & 159 & 118 \\
\hline PNNLS-10 & TEST 1 & 9.9 & 14 & 6.8 & 5.0 & 23 & 23 & 9.9 \\
\hline PNNLS-10 & TEST 2 & $200+$ & $200+$ & $200+$ & $200+$ & $200+$ & $200+$ & 200 \\
\hline PNNLS-10 & TEST 3 & 68 & 12 & 7.3 & 4.1 & $200+$ & 38 & 12 \\
\hline PNNLS-10 & TEST 4 & $200+$ & $200+$ & $200+$ & $200+$ & $200+$ & $200+$ & 200 \\
\hline PNNLS-11 & TEST 1 & 113 & $200+$ & 81 & 16 & $200+$ & $200+$ & 61 \\
\hline PNNLS-11 & TEST 2 & $200+$ & $200+$ & $200+$ & $200+$ & $200+$ & $200+$ & 200 \\
\hline PNNLS-11 & TEST 3 & $200+$ & $200+$ & $200+$ & 22 & $200+$ & $200+$ & 85 \\
\hline PNNLS-11 & TEST 4 & $200+$ & $200+$ & 80 & 57 & $200+$ & $200+$ & 120 \\
\hline PNNLS-12 & TEST 1 & 78 & 153 & 35 & 43 & 62 & 165 & 64 \\
\hline PNNLS-12 & TEST 2 & $200+$ & $200+$ & $200+$ & $200+$ & $200+$ & $200+$ & 200 \\
\hline PNNLS-12 & TEST 3 & 175 & $200+$ & $200+$ & $200+$ & 19 & $200+$ & 76 \\
\hline PNNLS-12 & TEST 4 & $200+$ & 176 & $200+$ & $200+$ & $200+$ & $200+$ & 196 \\
\hline PNNLS-13 & TEST 1 & 84 & 40 & 69 & 78 & $200+$ & 176 & 80 \\
\hline PNNLS-13 & TEST 2 & 43 & 53 & 109 & 49 & 131 & 56 & 62 \\
\hline PNNLS-13 & TEST 3 & 73 & 41 & 12 & 9.8 & 19 & 7.2 & 15 \\
\hline PNNLS-13 & TEST 4 & 7.8 & 7.1 & 4.1 & 42 & 188 & 53 & 11 \\
\hline PNNLS-14 & TEST 1 & 48 & 126 & $200+$ & $200+$ & 84 & 66 & 91 \\
\hline PNNLS-14 & TEST 2 & $200+$ & $200+$ & $200+$ & $200+$ & $200+$ & $200+$ & 200 \\
\hline PNNLS-14 & TEST 3 & $200+$ & $200+$ & $200+$ & $200+$ & $200+$ & $200+$ & 200 \\
\hline PNNLS-14 & TEST 4 & $200+$ & $200+$ & $200+$ & $200+$ & $200+$ & 139 & 186 \\
\hline PNNLS-15 & TEST 1 & 4.1 & 4.3 & 1.9 & 1.3 & 1.2 & 1.3 & 1.8 \\
\hline PNNLS-15 & TEST 2 & 5.2 & 10 & 2.1 & 3.9 & 1.9 & 4.4 & 3.4 \\
\hline PNNLS-15 & TEST 3 & $200+$ & $200+$ & $200+$ & $200+$ & $200+$ & $200+$ & 200 \\
\hline PNNLS-15 & TEST 4 & $200+$ & $200+$ & $200+$ & $200+$ & $200+$ & $200+$ & 200 \\
\hline PNNLS-16 & TEST 1 & $200+$ & $200+$ & $200+$ & $200+$ & $200+$ & $200+$ & 200 \\
\hline PNNLS-16 & TEST 2 & $200+$ & $200+$ & $200+$ & $200+$ & $200+$ & $200+$ & 200 \\
\hline PNNLS-16 & TEST 3 & $200+$ & $200+$ & $200+$ & $200+$ & $200+$ & $200+$ & 200 \\
\hline PNNLS-16 & TEST 4 & $200+$ & $200+$ & $200+$ & $200+$ & $200+$ & $200+$ & 200 \\
\hline
\end{tabular}




\begin{tabular}{|c|c|c|c|c|c|c|c|c|}
\hline $\begin{array}{l}\text { Subject } \\
\text { Number }\end{array}$ & $\begin{array}{c}\text { Test } \\
\text { Number }\end{array}$ & $\begin{array}{c}\text { Normal } \\
\text { Breathing } \\
\text { Fit Factor }\end{array}$ & \begin{tabular}{c|} 
Deep \\
Breathing \\
Fit Factor \\
\end{tabular} & $\begin{array}{l}\text { Head Side- } \\
\text { to-Side Fit } \\
\text { Factor } \\
\end{array}$ & $\begin{array}{l}\text { Jead Up and } \\
\text { Down Fit } \\
\text { Factor }\end{array}$ & $\begin{array}{c}\text { Talking } \\
\text { Fit } \\
\text { Factor }\end{array}$ & \begin{tabular}{|c|} 
Normal \\
Breathing \\
Fit Factor \\
\end{tabular} & $\begin{array}{c}\text { Overall } \\
\text { Fit Factor }\end{array}$ \\
\hline PNNLS-17 & " TEST 1 & 16 & 3.1 & 2.8 & $\overline{1.4}$ & 2.2 & 2.5 & 2.6 \\
\hline PNNLS-17 & TEST 2 & 7.3 & 4.6 & 8.8 & 0.6 & 7.9 & 2.9 & 2.2 \\
\hline PNNLS-17 & TEST 3 & 10 & 13 & 9.1 & 9.7 & 8.9 & 3.4 & 7.5 \\
\hline PNNLS-17 & TEST 4 & 130 & $200+$ & 198 & 16 & 38 & 21 & 39 \\
\hline PNNLS-18 & TEST 1 & 46 & $200+$ & 2.4 & 3.3 & 8.2 & 2.2 & 4.5 \\
\hline PNNLS-18 & TEST 2 & $200+$ & $200+$ & $200+$ & $200+$ & $200+$ & $200+$ & 200 \\
\hline PNNLS-18 & TEST 3 & 17 & 64 & 43 & 137 & 197 & 136 & 51 \\
\hline PNNLS-18 & TEST 4 & $200+$ & $200+$ & $200+$ & $200+$ & $200+$ & $200+$ & 200 \\
\hline PNNLS-19 & TEST 1 & $200+$ & 101 & 42 & $200+$ & 175 & $200+$ & 110 \\
\hline PNNLS-19 & TEST 2 & 91 & 107 & 160 & $200+$ & $200+$ & 82 & 123 \\
\hline PNNLS-19 & TEST 3 & 125 & 135 & 143 & $200+$ & $200+$ & $200+$ & 160 \\
\hline PNNLS-19 & TEST 4 & 140 & 94 & $200+$ & 119 & 149 & 75 & 117 \\
\hline PNNLS-20 & TEST 1 & $200+$ & $200+$ & $200+$ & $200+$ & $200+$ & 63 & 146 \\
\hline PNNLS-20 & TEST 2 & $200+$ & $200+$ & $200+$ & $200+$ & $200+$ & $200+$ & 200 \\
\hline PNNLS-20 & TEST 3 & 18 & 31 & $200+$ & 197 & 173 & 65 & 50 \\
\hline PNNLS-20 & TEST 4 & 35 & 19 & 32 & 4.9 & 101 & 35 & 17 \\
\hline PNNLS-21 & TEST 1 & 85 & 84 & 98 & 121 & 32 & 38 & 60 \\
\hline PNNLS-21 & TEST 2 & $200+$ & $200+$ & $200+$ & $200+$ & $200+$ & 83 & 162 \\
\hline PNNLS-21 & TEST 3 & $200+$ & $200+$ & $200+$ & $200+$ & 156 & 150 & 181 \\
\hline PNNLS-21 & TEST 4 & $200+$ & $200+$ & $200+$ & $200+$ & $200+$ & $200+$ & 200 \\
\hline PNNLS-22 & TEST 1 & $200+$ & $200+$ & $200+$ & $200+$ & $200+$ & $200+$ & 200 \\
\hline PNNLS-22 & TEST 2 & 26 & 29 & 31 & 46 & 44 & 21 & 30 \\
\hline PNNLS-22 & TEST 3 & $200+$ & 63 & 146 & 92 & $200+$ & $200+$ & 123 \\
\hline PNNLS-22 & TEST 4 & $200+$ & $200+$ & $200+$ & $200+$ & $200+$ & $200+$ & 200 \\
\hline PNNLS-23 & TEST 1 & 113 & 73 & 74 & 35 & 63 & 117 & 68 \\
\hline PNNLS-23 & TEST 2 & 56 & 57 & 43 & 30 & 38 & 26 & 38 \\
\hline PNNLS-23 & TEST 3 & $200+$ & $200+$ & $200+$ & $200+$ & $200+$ & $200+$ & 200 \\
\hline PNNLS-23 & TEST 4 & $200+$ & $200+$ & $200+$ & $200+$ & $200+$ & $200+$ & 200 \\
\hline PNNLS-24 & TEST 1 & $200+$ & $200+$ & $200+$ & $200+$ & $200+$ & 139 & 186 \\
\hline PNNLS-24 & TEST 2 & $200+$ & $200+$ & $200+$ & $200+$ & $200+$ & $200+$ & 200 \\
\hline PNNLS-24 & TEST 3 & 163 & $200+$ & $200+$ & $200+$ & $200+$ & $200+$ & 193 \\
\hline PNNLS-24 & TEST 4 & $200+$ & $200+$ & $200+$ & 119 & $200+$ & 93 & 153 \\
\hline PNNLS-25 & TEST 1 & $200+$ & $200+$ & $200+$ & $200+$ & 187 & $200+$ & 198 \\
\hline PNNLS-25 & TEST 2 & 108 & 81 & 159 & 71 & 79 & 133 & 96 \\
\hline PNNLS-25 & TEST 3 & 50 & 74 & 119 & 27 & 21 & 13 & 29 \\
\hline PNNLS-25 & TEST 4 & 13 & 3.9 & 29 & 16 & 17 & 4.0 & 8.1 \\
\hline
\end{tabular}




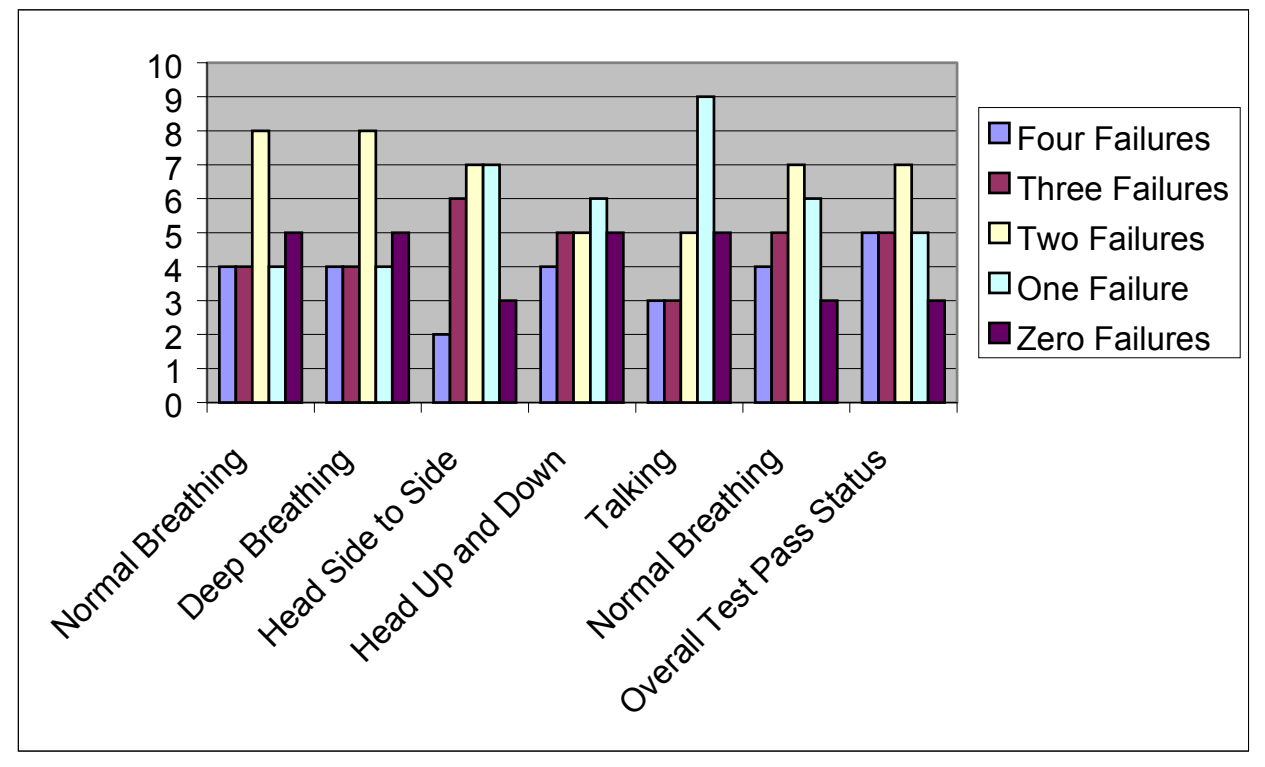

Figure 7. Summary of the Pass-Fail Rates for Each of the Exercises and the Overall Test Pass Status. Note that the pass-failure rates were similar for all exercises, indicating that the Lepestok-200 respirator has a similar performance for all exercises. The criteria for passing is a fit factor greater than or equal to 100 .

Table 2 and Figure 8 show the percent of tests exceeding a given overall fit factor. In the total of 100 tests, $95 \%$ of the overall fit factors were greater than 3 , more than $80 \%$ of the overall fit factors were greater than 14, approximately $50 \%$ were greater than 86 , and $20 \%$ were greater than 200 . It would be desirable for the respirator to provide a fit factor greater than 100 for more than $95 \%$ of the subjects. In these tests, more than half of the subjects have less than the target fit factor of 100 . This means that their fit factor in the real work environment might be less than 10 .

As shown in Table 3, a significant and sustained improvement in fit factor was observed after the initial test, indicating that the subjects benefited from the knowledge gained in the first of the four quantitative fit tests. The improved performance was probably due to "learning" that occurred about how to adjust the contour and tightness of the respirator around the face.

The learning experience from the first test resulted in a doubling of the fit factor from 3 to 6 for the $95^{\text {th }}$ percentile of subjects. Table 4 and Figure 9 show the percentage of tests exceeding a given overall fit factor for tests 2 through 4 . In the 75 tests conducted after the initial test for each individual, $95 \%$ of the overall fit factors were greater than 6 , more than $80 \%$ of the overall fit factors were greater than 23 , and $50 \%$ were greater than 116 . 
Table 2. Percentage of All Tests Exceeding a Given Overall Fit Factor. Penetration values (the inverse of fit factor) are also shown.

\begin{tabular}{|c|c|c|}
\hline Percent & Fit Factor & Penetration (\%) \\
\hline \hline 5 & 3.1 & 32.5 \\
\hline 10 & 7.3 & 13.8 \\
\hline 15 & 11.9 & 8.4 \\
\hline 20 & 14.0 & 7.1 \\
\hline 25 & 26.3 & 3.8 \\
\hline 30 & 37.1 & 2.7 \\
\hline 35 & 49.7 & 2.0 \\
\hline 40 & 61.6 & 1.6 \\
\hline 45 & 75.1 & 1.3 \\
\hline 50 & 86.5 & 1.2 \\
\hline 55 & 107.8 & 0.9 \\
\hline 60 & 118.8 & 0.8 \\
\hline 65 & 142.8 & 0.7 \\
\hline 70 & 182.5 & 0.5 \\
\hline 75 & 193.8 & 0.5 \\
\hline 80 & 200 & 0.5 \\
\hline 85 & 200 & 0.5 \\
\hline 90 & 200 & 0.5 \\
\hline 95 & 200 & 0.5 \\
\hline
\end{tabular}

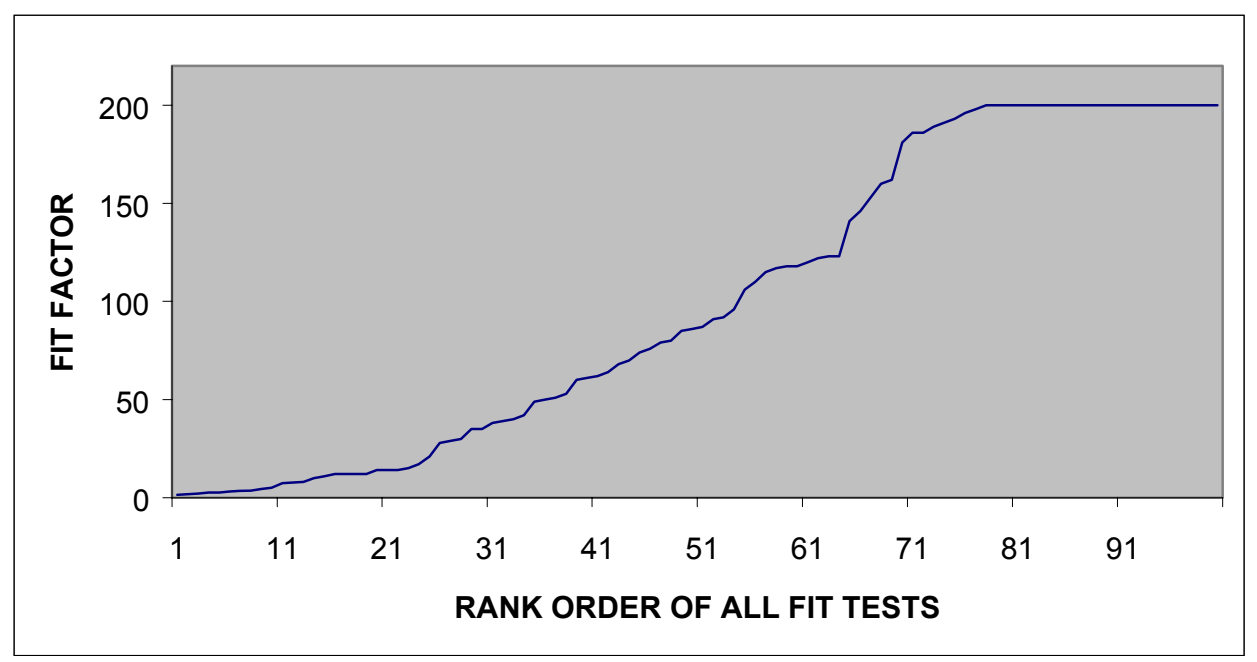

Figure 8. Rank Order of the Overall Fit Factors for All Fit Tests from Lowest Value to Highest Value. Note that $50 \%$ of the tests involved fit factors greater than 86 , while $90 \%$ of the tests involved fit factors greater than 7 , and $95 \%$ of the tests involved fit factors greater than 3 . 
Table 3. Summary of the Overall Pass-Fail Rates for all 25 Subjects in Each of the Four Tests. The consistently higher pass rate for tests 2, 3, and 4 indicates that the subjects benefited from the knowledge gained in the first quantitative fit test. The criteria for passing was a fit factor greater than or equal to 100 .

\begin{tabular}{||c|c|c|c|c|c||}
\hline Results & Test 1 & Test 2 & Test 3 & Test 4 & All Tests \\
\hline Pass & 7 & 13 & 12 & 14 & 46 \\
\hline Fail & 18 & 12 & 13 & 11 & 54 \\
\hline
\end{tabular}

Table 4. Percentage of Tests 2 through 4 Exceeding a Given Overall Fit Factor. Penetration values (the inverse of fit factor) are also shown. Note that experience gained in the first fit test has apparently resulted in improved fit factors for tests 2 through 4.

\begin{tabular}{|c|c|c|}
\hline Percent & Fit Factor & Penetration (\%) \\
\hline \hline 5 & 6.1 & 16.3 \\
\hline 10 & 12 & 8.3 \\
\hline 15 & 14 & 7.1 \\
\hline 20 & 23.6 & 4.2 \\
\hline 25 & 35 & 2.9 \\
\hline 30 & 39.9 & 2.5 \\
\hline 35 & 61.5 & 1.6 \\
\hline 40 & 80.2 & 1.2 \\
\hline 45 & 91.3 & 1.1 \\
\hline 50 & 116 & 0.9 \\
\hline 55 & 120.3 & 0.8 \\
\hline 60 & 137.4 & 0.7 \\
\hline 65 & 170.6 & 0.6 \\
\hline 70 & 193.3 & 0.5 \\
\hline 75 & 200 & 0.5 \\
\hline 80 & 200 & 0.5 \\
\hline 85 & 200 & 0.5 \\
\hline 90 & 200 & 0.5 \\
\hline 95 & 200 & 0.5 \\
\hline
\end{tabular}




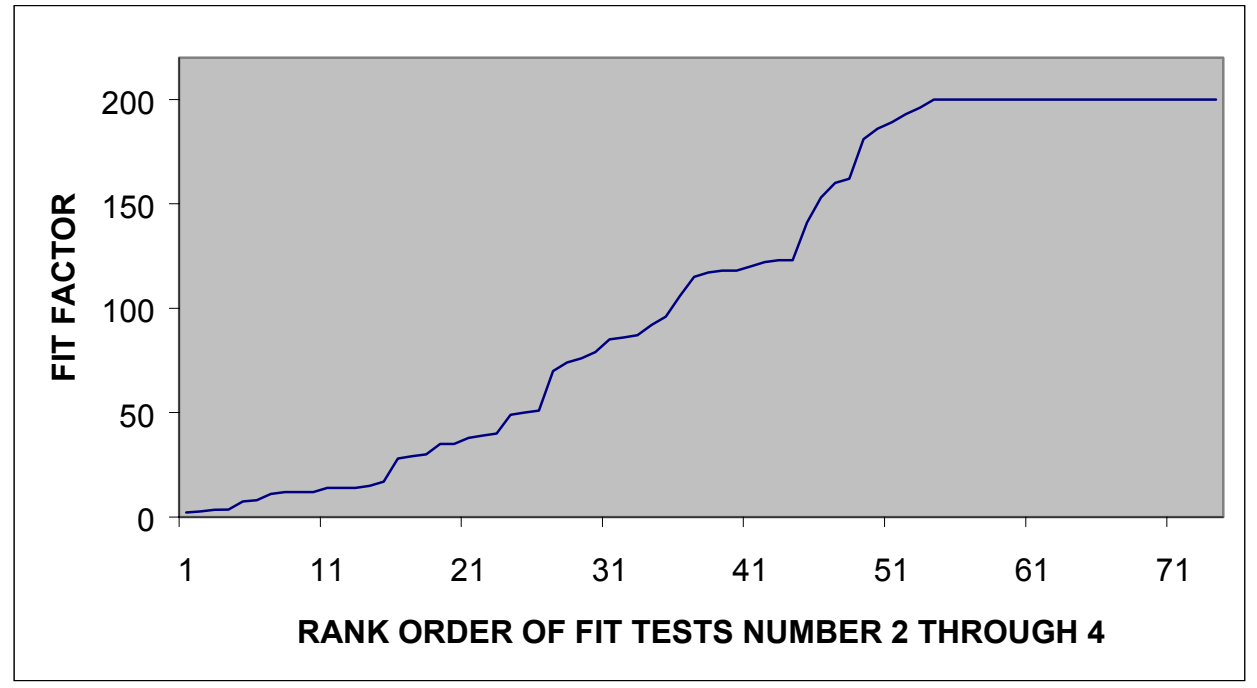

Figure 9. Rank Order of the Overall Fit Factors for Fit Tests 2 through 4, from Lowest Value to Highest Value. Note that $50 \%$ of the tests involved fit factors greater than 116 , while $90 \%$ of the tests involved fit factors greater than 12 , and $95 \%$ of the tests involved fit factors greater than 6 .

Table 5 compares the performance of the Lepestok- 200 in this study to the performance of 21 commercially available N95 respirators that were tested by the National Institute for Occupational Safety and Health (NIOSH) (Coffey et al. 1999a). The comparison is based on the $95^{\text {th }}$ percentile of total percent penetration. The best performing commercially available respirator provided a penetration of less than $6 \%$. That translates to a fit factor of $1 / 0.06=17$. The poorest performing commercially available respirator provided a penetration of $88 \%$, which translates to a protection factor of only 1.1 . When the results of all four tests are used, the Lepestok-200 performed better than 5 of the commercial respirators and poorer than 16 of the commercial respirators. When the results for tests 2 through 4 are used, the Lepestok-200 performed better than 13 of the commercial respirators and poorer than 8 of the commercial respirators. These results reinforce the general conclusion that quantitative fit-testing can make an important contribution to ensuring that proper protection factors are achieved for workers. 
Table 5. Performance of the Lepestok-200 Filtering Facepiece Respirator Compared to the Performance of 21 Other Models of N95 Respirators Tested by NIOSH. (NIOSH data from Coffey et al 1999a)

\begin{tabular}{|c|c|c|}
\hline Overall Rank & Respirator Model & $\begin{array}{c}\text { 95th Percentile of Total } \\
\text { Penetration }\end{array}$ \\
\hline 1 & 1 & 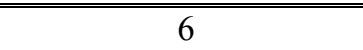 \\
\hline 2 & 8 & 6 \\
\hline 3 & 2 & 7 \\
\hline 4 & 18 & 7 \\
\hline 5 & 7 & 10 \\
\hline 6 & 6 & 11 \\
\hline 7 & 10 & 12 \\
\hline 8 & 16 & 13 \\
\hline 9 & $\begin{array}{l}\text { Lepestok-200 results } \\
\text { for tests } 2-4\end{array}$ & 16 \\
\hline 10 & 3 & 18 \\
\hline 11 & 9 & 18 \\
\hline 12 & 15 & 19 \\
\hline 13 & 13 & 21 \\
\hline 14 & 21 & 24 \\
\hline 15 & 14 & 26 \\
\hline 16 & 5 & 31 \\
\hline 17 & 19 & 32 \\
\hline 18 & $\begin{array}{l}\text { Lepestok-200 results } \\
\text { for all } 4 \text { tests }\end{array}$ & 32.5 \\
\hline 19 & 11 & 33 \\
\hline 20 & 12 & 41 \\
\hline 21 & 17 & 50 \\
\hline 22 & 20 & 61 \\
\hline 23 & 4 & 88 \\
\hline
\end{tabular}




\section{Conclusions and Recommendations}

The performance of the Lepestok-200 has been shown to exceed the design criteria of fit factor $>200$ in $20 \%$ of the tests done in this study and to exceed a fit factor of approximately 100 in $50 \%$ of the tests. Fit-testing may be needed to provide the training and information needed to improve the fit factor to $>100$ for a greater percentage of subjects. As shown in this report and as reported in papers cited above for other N95-type respirators, quantitative fit-testing can identify workers who may benefit from a different size or design of respirator and can help train wearers of the Lepestok-200 to achieve higher protection factors. 


\section{Acknowledgments}

This work was performed at the Lovelace Respiratory Research Institute under Contract No. 298148A-N Media from the Pacific Northwest National Laboratory International Nuclear Safety Program. Collaboration of the Chornobyl scientists is gratefully acknowledged. Thanks to our enthusiastic and loyal subject volunteers, to Charlotte Pacheco of the LRRI Institutional Review Board, and to Steven Rohrer, Carol Petty, and William Schleyer for useful discussions and help in planning the study. Thanks to Judson Kenoyer of PNNL for his useful review and comments. We are grateful for the significant information and discussion on the state of the art for respirator fit-testing that was provided by Christopher C. Coffey, Ernest S. Moyer, and Paul A. Jensen of the National Institute for Occupational Safety and Health (NIOSH) in Morgantown, WV. 


\section{References}

American Industrial Hygiene Association (AIHA). 1985. "Respirator Performance Terminology."

Letter to the Editor from the American Industrial Hygiene Association Respiratory Protection Committee, Am. Ind. Hyg. Assoc. J. 46(5):B-22-24.

American National Standards Institute (ANSI). 1992. American National Standard for Respiratory Protection. ANSI Z88.2-1992, American National Standards Institute, New York, NY.

Coffey, C.C., D.L. Campbell, W.R. Myers, Z. Zhuang, and S. Das. 1998a. “Comparison of Six Respirator Fit Test Methods with an Actual Measurement of Exposure in a Simulated Health-Care Environment: Part I - Protocol Development”, Am. Ind. Hyg. Assoc. J. 59:852-861.

Coffey, C.C, D.L. Campbell, W.R. Meyers, and Z. Zhuang. 1998b. "Comparison of Six Respirator FitTest Methods with an Actual Measurement of Exposure in a Simulated Health Care Environment: Part II - Method Comparison Testing." Am. Ind. Hyg. Assoc. J. 59: 862-870.

Coffey, C.C, D.L. Campbell, and W.R. Myers. 1999a. "Comparison of Six Respirator Fit Test Methods With an Actual Measurement of Exposure in a Simulated Health-Care Environment: Part III - Validation Testing." Am. Ind. Hyg. Assoc. J. 60: 363-366.

Coffey, C.C., Z. Zhuang, and D. Campbell. 1999b. "Simulated Workplace Performance of N95 Respirators." Am. Ind. Hyg. Assoc. J. 60: 618-624.

Coffey, C.C, Z. Zhuang, D.L. Campbell, and W.R. Myers. 2000. Quantitative Fit-Testing of N95 Respirators: Part II -Results, Effect of Filter Penetration, Fit-Test, and Pass/Fail Criteria on Respirator Performance. National Institute of Occupational Safety and Health, Morgantown, WV.

GOST. 1976. Labor Safety Standards Series: Lepestok ShB-1 Respirators - Technical Specifications, GOST 12.4.28-76, State Standard (GOST) of the Union of Soviet Socialists Republics.

Hack, H., E.C. Hyatt, B.J. Held, T.O. Moore, C.P. Richards, and J.T. McConville. 1974. Selection of Respirator Test Panels Representative of U.S. Adult Facial Sizes. Report No. LA-5488, UC-41, Los Alamos National Laboratory, Los Alamos, NM.

Hoover, M.D., A.F. Fencl, and G.J. Vargo. 1999. Independent Evaluation of Air Filter Media from Chornobyl. PNNL-13053/LRRI-19990901, Pacific Northwest National Laboratory, Richland, WA, and Lovelace Respiratory Research Institute, Albuquerque, NM.

National Institute of Occupational Safety and Health (NIOSH). 1996. Title 42 Code of Federal Regulations Part 84, Approval of Respiratory Protective Devices, 42 CFR 84, Office of the Federal Register, Washington, DC. 
National Institute of Occupational Safety and Health (NIOSH). 1998. "Laboratory Performance Evaluation of N95 Filtering Facepiece Respirators," Morbidity and Mortality Weekly Report 47(48):

1045-1049.

Occupational Safety and Health Administration (OSHA). 1998. Title 29, Code of Federal Regulation, Parts 1910 and 1926. "Respiratory Protection: Final Rule." Occupational Safety and Health Administration, Federal Register 63(5): 1152-1300, January 8, 1998.

Suhoruchkin, A.K. 2000. Report Regarding Assessments of the Effectiveness of the Lepestok Respirator (An analysis of Report PNNL-13053/LRRI-19990901). The Shelter, Chornobyl, Ukraine.

TSI. 1991. Operation and Service Manual for the TSI Model 8020 PortaCount Plus. TSI Incorporated, St. Paul, MN, July 1991.

TSI. 1998a. Operation and Service Manual for the TSI Model 8095 N95-Companion to the PortaCount Plus. TSI Incorporated, St. Paul, MN, November 1998.

TSI. 1998b. Operation and Service Manual for the TSI Model 8026 Particle Generator. TSI Incorporated, St. Paul, MN, January 1998.

Zhuang, Z., C. C. Coffey, W. R. Myers, J. Yang, and D. L. Campbell. 2000. Quantitative Fit-Testing of N95 Respirators: Part I-Method Development. National Institute of Occupational Safety and Health, Morgantown, WV. 
PNNL-13581

\section{Distribution}

No. of Copies

ONSITE

17 Pacific Northwest National Laboratory

$\begin{array}{ll}\text { George J. Vargo (5) } & \text { K3-56 } \\ \text { Brian W. Smith } & \text { K8-46 } \\ \text { Jennifer E. Tanner } & \text { K3-55 } \\ \text { Daniel P. Couch } & \text { K8-05 } \\ \text { James C. Wiborg } & \text { K7-84 } \\ \text { Robert L. Moffitt } & \text { K7-64 } \\ \text { J.C. McDonald } & \text { K3-53 } \\ \text { Gary R. Petersen } & \text { K7-68 } \\ \text { K.L. Soldat } & \text { K3-53 } \\ \text { M.E. Hevland } & \text { P7-01 } \\ \text { D.K. Kreid } & \text { K7-68 } \\ \text { George J. Carr } & \text { K3-54 } \\ \text { G.R. Bilyard } & \text { K3-54 }\end{array}$

Distr. 1 